\title{
Dinâmicas Comerciais entre Brasil e Cabo Verde: uma análise acerca do papel das rabidantes cabo-verdianas no mercado informal brasileiro ${ }^{1}$
}

Tatiana Raquel Reis Silva

\section{Resumo}

Este trabalho visa analisar as dinâmicas comerciais estabelecidas entre Brasil e Cabo Verde a partir da aquisição de produtos pelas rabidantes em Fortaleza, no Estado do Ceará. Essas mulheres, conhecidas como rabidantes, comercializam produtos adquiridos não só em outros países africanos, mas também europeus e do continente americano, como EUA e Brasil. Neste sentido, discorreremos sobre o início das trocas comerciais, o crescimento da informalidade e seu impacto na economia dos dois países, assim como os principais locais de venda e, produtos adquiridos por essas mulheres no território nacional.

Palavras-chave: comércio informal; rabidantes; mercado brasileiro

\section{Commercial Dynamics between Brazil and Cape Verde: an analysis of the role of rabidantes in the informal Brazilian market}

\author{
Abstract \\ This work analyzes the trade dynamics established between \\ Brazil and Cape Verde as from acquisition of the products by ra-
}

\footnotetext{
* Este artigo faz parte de uma pesquisa mais ampla que foi desenvolvida em minha tese de doutorado, defendida no Programa de Pós-graduação em Estudos Étnicos e Africanos - POSAFRO/UFBA, intitulada "A arte de comerciar: gênero, identidades e empoderamento feminino no comércio informal transatlântico das rabidantes cabo-verdianas".

${ }^{* *}$ Professora adjunta do Departamento de História e Geografia da Universidade Estadual do Maranhão.Email: tatianaraquel.reis@gmail.com.
} 
DINÂMICAS COMERCIAIS ENTRE BRASIL E CABO VERDE: UMA ANÁLISE ACERCA DO PAPEL DAS RABIDANTES CABO-VERDIANAS NO MERCADO INFORMAL BRASILEIRO

bidantes in Fortaleza, State of Ceará. These women, known as rabidantes, purchased products in other African countries and the European and American continent, as the USA and Brazil. Therefore, it will discuss the beginning of this trade, the growth of the informal economy and its impact on the two countries as well the main points of sales and the products acquired. Keywords: informal trade; rabidantes; Brazilian market

Brasil e Cabo Verde têm desenvolvido laços de solidariedades desde o período colonial, pátrias irmãs como propagavam os discursos da época, vivenciaram processos de dominação e colonização muito similares, que ecoaram nas produções literárias dos claridosos ${ }^{3}$, enfatizando as proximidades do ambiente social, cultural e físico do arquipélago com o nordeste brasileiro, especialmente com o Estado do Ceará. Essa histórica relação atualmente tem sido reestabelecida pelas chamadas rabidantes, mulheres comerciantes que adquirem produtos no mercado informal brasileiro e revendem em seu país.

As rabidantes desempenham um importante papel na economia cabo-verdiana, elas são responsáveis pelo abastecimento da população local, comercializando não apenas gêneros alimentícios como também, roupas, calçados, lingeries, bijuterias e uma infinidade de outros produtos. Em Cabo Verde o comércio informal tem sido um dos principais sustentáculos econômicos e no Brasil vem ganhando cada vez mais adeptos. Vale destacar que esta é uma prática essencialmente feminina, na maioria dos países da

3 A Revista Claridade, que dá nome ao movimento claridoso, foi fundada em 1930 como uma forma de denunciar as questões sociais vivenciadas pelo arquipélago, tecendo críticas ao governo português e enfatizando a necessidade de repensar a identidade cabo-verdiana que se forjava no contexto pós-independência. Dentre os fundadores pode-se destacar Baltasar Lopes, Manuel Lopes e Jorge Barbosa. Os claridosos, como ficaram conhecidos, sofreram forte influência de autores brasileiros como Lins dos Regos, Jorge Amado e Graciliano Ramos. 
África subsaariana, as atividades informais são tradicionalmente protagonizadas por mulheres.

De acordo com Hopkins (1995), este fenômeno advém desde o período pré-colonial e, em alguns lugares, desapareceu completamente durante a colonização para ressurgir com grande força no pós-independência, especialmente, naqueles países que aplicaram modelos de desenvolvimento com medidas de estabilização e ajustamento estrutural. Em Cabo Verde o acelerado processo de concentração urbana tem provocado um aumento considerável da população que vive na cidade e não vem sendo acompanhado pelo ritmo de produção de empregos no setor formal da economia, afetando diretamente a população feminina.

Desde a sua independência, em especial a partir dos anos 1990, o país vem adotando como estratégia de desenvolvimento a inserção de forma dinâmica na economia mundial, com o intuito de solucionar alguns dos seus principais problemas: proporcionar emprego e renda a uma grande parcela da população empobrecida. Na primeira fase de implementação do Plano Nacional de Luta contra a Pobreza de 1999, ficou definido como uma das principais estratégias e medidas políticas a ser seguida, o combate a pobreza no grupo de mulheres, particularmente, entre aquelas chefes de família ${ }^{4}$, através da integração nos círculos econômicos, da alfabetização e formação profissional e do reforço da educação e da saúde.

Grassi (2003) assinala que as mulheres representam cerca de $64 \%$ dos analfabetos no país, possuem as menores taxas de instrução e possibilidade de frequentar escolas, sobretudo, aquelas que vivem no meio rural. Isso tem contribuído para a fraca inserção no mercado de trabalho formal. No entanto, desde 
1990, com o apoio político internacional, os níveis educacionais alcançaram índices satisfatórios, acarretando um maior acesso da população a educação. Isso pode ser verificado no aumento das taxas de alfabetização no ensino básico, secundário e superior. Todavia, apesar do crescimento econômico e consequente geração de emprego, registrado nos últimos anos, não significou a diminuição da pobreza relativa quando analisada segundo critérios de gênero 5 .

Esses indicadores têm corroborado para o crescimento do setor informal em Cabo Verde e feminização dessa atividade. Neste contexto é possível perceber o lugar de importância ocupado pelas rabidantes em uma sociedade que importa quase $80 \%$ de tudo que é consumido. A aquisição dos produtos ocorre em demais países do continente africano, como Senegal, Gâmbia, Guiné-Conakri e Marrocos; europeus, como França e Holanda; e americanos, como Estados Unidos e Brasil. Este último se destaca pelos voos operados semanalmente pela Empresa de Transportes Aéreos Cabo-Verdianos (TACV), que ligam Fortaleza a Cidade da Praia, capital do país ${ }^{6}$.

Assim, o presente artigo pretende analisar as dinâmicas comerciais estabelecidas entre Brasil e Cabo Verde a partir da aquisição de produtos pelas rabidantes em Fortaleza, no Estado do Ceará. Dessa forma será preciso discorrer sobre o início das trocas comerciais, o crescimento da informalidade e seu impacto na economia dos dois países, assim como os principais locais de venda e os produtos adquiridos por essas mulheres no território nacional.

5 Para maiores informações ver Furtado (2008).

6 Atualmente os voos ocorrem todas as quintas-feiras e duram, em média, três horas e meia. 
Relações comerciais entre Brasil e Cabo Verde

De acordo com Muniz (2008) a inserção brasileira no comércio internacional visando o baixo custo, melhor qualidade dos produtos, atualização tecnológica e estreitamento das relações no eixo sul-sul, proporcionou a inclusão no rol dos países detentores de vantagens comerciais. Esse contexto de intensas trocas mercantis contribuiu para sanar a dívida externa nacional, fazendo com que o Brasil passasse de devedor a credor externo. A partir deste momento é possível visualizar toda uma empreitada do governo em estabelecer parcerias, e o mercado de consumo africano passou a ter uma importância estratégica na política de intensificação das exportações.

A Câmara de Comércio Afro-brasileira, criada em 1968, constitui um reflexo das medidas implementadas que visavam uma maior aproximação entre o Brasil e o continente africano e que possibilitou o desenvolvimento de negócios, atividades culturais, científicas, tecnológicas e de cooperação. A Câmara de Comércio, que teve Adalberto Camargo como presidente e idealizador, congregava comerciantes, empresários e industriais que compartilhavam interesses econômicos e objetivavam:

a) promover a cooperação das entidades congêneres entre os respectivos países do continente e o Brasil; b) instituir e desenvolver esquemas informativos sobre mercadorias, tarifas, direitos e isenções aduaneiras, câmbio, navegação, tratados comerciais, legislação e jurisprudência relacionadas a convênios bilaterais; c) promover, organizar ou participar de congressos, seminários, simpósios, conferências, feiras, exposições e reuniões; d) formular proposições e elaborar programas visando o aperfeiçoamento das trocas comerciais entre Brasil e 
África; e) organizar, coordenar e prestar assistência a missões comerciais brasileira a África e vice-versa; elaborar e publicar análises setoriais e conjunturais das economias africanas; f) recepcionar delegações dos países do continente africano em visita ao território brasileiro; promover a capacitação de recursos humanos para as atividades do comércio internacional, qualificando mão-de-obra especializada; g) editar revistas, jornais, boletins informativos, monografias, perfis promocionais e publicações similares, a fim de divulgar tudo que possa interessa à promoção, bem como à intensificação de atividades diplomáticas, comerciais e culturais entre o Brasil e o continente. (SANTANA, 2004: 86)

Inicialmente a Câmara estabeleceu contatos e realizou levantamentos de dados sobre o mercado de consumo africano visando a edificação de um acervo documental e a constituição de uma biblioteca. Em maio de 1972 foi organizado, em São Paulo, a $1^{\text {a }}$ Semana Afro-brasileira que contou com a participação de vários representantes e embaixadores africanos. Naquele mesmo ano, ocorreu a famosa viagem do então Ministro das Relações Exteriores Gibson Barbosa a diversos países da África Ocidental, e que contou com uma intensa agenda de acordos, visitas diplomáticas e cooperações comerciais, inaugurando o período que ficou conhecido como "os anos dourados da política africana no Brasil".

Em 1973 foi realizada a 1ํㅗ Missão Comercial Brasileira a Países da África, organizada pelo Itamaraty em parceria com a Câmara de Comércio Afro-brasileira, onde participaram representantes do governo e de indústrias brasileiras, como a Petrobrás e Eletrobrás. A delegação percorreu o Senegal, Costa do Marfim, Gana, Togo, República Popular do Benin, Nigéria, Camarões, Zaire e Líbia, firmando acordos que objetivavam a construção de estradas, hidrelétricas, bem como a venda de equipamentos. Além disso, contou com uma amostra itinerante de mais de 200 
produtos brasileiros, apresentados em exposições montadas em cada uma das capitais visitadas.

Os resultados desses convênios foram extremamente significativos, de acordo com Santana (2004), que analisou dados do Banco Central referentes as exportações brasileiras para o continente africano, no ano de 1974 houve um crescimento de $129 \%$. Nos anos de 1970 e mais precisamente 1980, a África, em especial a Nigéria, constituía um dos principais vetores de expansão do comércio brasileiro pelo mundo, sobretudo, em função do petróleo. Este último representou cerca de $70 \%$ de todas as importações nacionais. Como resultado das relações tão próximas entre os dois países, foram efetivados voos regulares ligando Rio de Janeiro a Lagos ${ }^{7}$.

A partir deste momento ocorre a mudança do principal eixo comercial brasileiro, antes ligado a África Austral, em especial a África do Sul, para o lado ocidental do continente. Uma das razões para essa transformação foram as tensões políticas vivenciadas naquela região advindas do apartheid, que havia se tornado uma problemática latente e longe de alcançar solução, enquanto que a parte ocidental africana se apresentava como mais estratégica, pois compreendia as três grandes comunidades linguísticas: francófona, lusófona e anglófona. Influenciado por este contexto o então presidente João Baptista Figueiredo empreendeu uma nova incursão aos países africanos.

Na ocasião, em março de 1983, visitou Guiné-Bissau e Cabo Verde, reconhecendo o processo de independência de toda a África portuguesa e reforçando a cooperação brasileira a estes países. De acordo com Saraiva (1996), a viagem revestiu-se em dois valores: o primeiro de ordem material, traduzido no re-

7 Estes voos eram operados pela antiga Varig que naquela conjuntura também possuia voos ligando Cabo Verde e Brasil. Como será possível perceber ao longo do texto, este foi o impulso inicial de inserção das rabidantes no território nacional. 
conhecimento recíproco da estratégia comercial brasileira no continente; e o segundo de cunho simbólico, concebido pelo reforço da identidade atlântica que unia as duas regiões. É exatamente a partir da reativação dos discursos culturalistas, que enfatizavam as afinidades históricas com os povos da África, nomeadamente os de língua portuguesa, que se edifica o principal eixo de sustentação da política externa brasileira voltada para o continente nos anos de 1990, reforçados ainda pela criação da Comunidade de Países de Língua Portuguesa (CPLP) em julho de 1996.

Vale ressaltar que essa havia sido uma idéia gestada desde os anos de 1989, durante o governo do presidente José Sarney, que almejava a constituição do Instituto da Língua Portuguesa, com o objetivo de promover a defesa do idioma como patrimônio comum dos países e povos que o utilizam como língua nacional ou oficial, assim como estimular o desenvolvimento das relações culturais. $\mathrm{O}$ intuito maior da comunidade era operacionalizar a integração econômica regional, abrindo espaços de aproximação em que os interesses econômicos fossem motivados por valores políticos e culturais.

O passo inicial para a aproximação política e econômica entre Brasil e Cabo Verde se deu no ano de 1999, ocasião em que ocorreu o perdão parcial da dívida externa cabo-verdiana com o Brasil e o reescalonamento dos valores atrasados ${ }^{8}$. A remissão de um débito que totalizava quase $50 \%$ da dívida externa do país possibilitou a reestruturação da economia local e a consolidação das bases para inserção no mercado internacional. A partir deste momento o governo de Cabo Verde buscou fortalecer os acordos bilaterais dando impulso aos aportes de cooperação, visando o desenvolvimento socioeconômico e a melhoria de in- 
fraestrutura urbana e portuária. Neste contexto, o mercado brasileiro obteve destaque significativo ${ }^{9}$.

No ano 2001 foram firmados acordos bilaterais entre os dois países na expectativa de efetivação de trocas comerciais formais. Estes convênios ganharam maior projeção a partir dos incentivados da Organização das Nações Unidas (ONU) através da realização de pactos internacionais e, também, pelo fortalecimento das relações político-governamental por intermédio da CPLP. Um importante evento para a concretização dessas medidas foi o Encontro Brasil-África, realizado pelo governo brasileiro, em 2003 na cidade de Fortaleza e que almejava a ampliação das relações turísticas e comerciais com o continente africano. Essas ações têm possibilitado trocas econômicas expressivas nos últimos anos entre os dois países.

O intenso fluxo comercial dos cabo-verdianos no Brasil atualmente é marcante nos Estados de São Paulo e do Ceará. Este último tem se destacado devido a ativação do modal aéreo da TACV no ano de 2001. De acordo com Muniz (2008) a priori o saldo comercial do Ceará com Cabo Verde era de US\$139.551, free on board, o que correspondia naquela época a 0,026\% das exportações cearense. Em 2003 o valor exportado chegou a US\$ 568.435 dólares e, em 2004, saltou para US\$ 3.121.927, numa clara demonstração do quanto a implantação do modal aéreo facilitou as relações comerciais entre os países.

Inicialmente os voos estavam voltados para o deslocamento de empresários e investidores interessados em dinamizar as trocas econômicas nos dois lados do atlântico. Para fortalecer essa movimentação comercial, foi montada toda uma estrutura que

9 Muniz (2008) assinala que na década de 1990 a economia cabo-verdiana foi beneficiada pelo crescimento dos investimentos externos, sobretudo, no setor bancário e hoteleiro com a venda das principais empresas estatais e de $80 \%$ do sistema financeiro a grupos estrangeiros, principalmente, Portugal. 0 fluxo de remessas da população emigrada também contribuiu para este processo. 
possibilitasse a circulação pela capital do estado. Os vôos vindos de Cabo Verde eram organizados semanalmente em um grupo de 50 pessoas, que eram ciceroneados por gerentes da própria TACV responsáveis pela logística de acompanhamento e orientação que estes comerciantes necessitavam, tais como: roteiro de locais para compra, hospedagem e alimentação; troca de Dólar por Real; viagens de negócios à região metropolitana e a municípios próximos.

A partir deste momento que é possível perceber a entrada significativa das rabidantes no território nacional e, consequente, comercialização no mercado informal da cidade de Fortaleza. No entanto, vale ressaltar que a inserção dessas mulheres em nosso país se dá desde o ano de 1993, com os voos da antiga Varig ligando Cabo Verde e Brasil, e que tinha como destino principal o Rio de Janeiro. Naquela conjuntura os voos eram quinzenais e a aquisição de produtos se dava, sobretudo, na capital do estado. Todavia, é com ativação do modal aéreo operacionalizado pela TACV que esta dinâmica de comercialização ganha contornos mais expressivos.

De fato foi somente a partir de 2001 que se tornou mais recorrente e constante a vinda das rabidantes para o Brasil, isso não apenas em função da redução no horário dos voos, mas também no valor das passagens. Estes fatores atrelados a importância crescente que a economia informal ganhava na capital cearense, reservou a Fortaleza o papel de destaque em meio aos destinos dessas mulheres. Nos últimos anos, São Paulo também tem adquirido proeminência na concorrência pelo menor preço e maior diversidade de produtos. 
As rabidantes cabo-verdianas e o mercado informal brasileiro

A rabidancia constitui uma prática fundamental na sociedade cabo-verdiana, fazendo com que as mulheres que desenvolvem essa atividade adquiram um status de importância na economia local. A compra e venda de produtos em feiras, ruas e mercados tem impulsionado as rabidantes a viajarem por diversos países na busca por produtos baratos advindos em sua maioria do setor informal. Em Cabo Verde, notadamente na Cidade da Praia, a informalidade tem gerado emprego e renda a uma parcela significativa da população local, majoritariamente, feminina.

No Brasil este tipo de comércio tem ganhado um número crescente de adeptos e em Fortaleza, frente a falta de crédito, de qualificação e de vagas no mercado formal, um aglomerado de trabalhadores ocupam as praças, cruzamentos de ruas, mercados e feiras, vendendo roupas, calçados, lingeries e biquínis no centro da cidade. De acordo com o presidente da Associação dos Vendedores Ambulantes Autônomos do Estado do Ceará, Antônio Amaro da Silva, em entrevista ao jornal O Povo, o desemprego é a principal causa para a grande procura pela informalidade, aliado a falta de qualificação que conta muito na hora de conseguir uma vaga de trabalho no comércio formal.

Segundo o presidente a maioria dos vendedores é oriunda do interior do Estado, da agricultura ou da construção civil e muitos destes não possuem qualificação. "No mercado informal, não é preciso qualificação para comprar ou vender e muitas empresas exigem níveis elevados de educação", acrescenta. Antônio destaca um outro problema que tem dificultado a inserção dessas pessoas no comércio formal: a burocracia e a falta de crédito. "Se houvesse maior incentivo para abrir linha de crédito, por meio de instituições privadas ou públicas, a gente poderia se estabele- 
cer para legalizar. É necessário a formação de cursos de vendas. Tem que ter estudo".

A formalização deste tipo de atividade tem sido exigida pelo Sindicato do Comércio Varejistas de Fortaleza (Sindilojas) na medida em que os produtos que são comercializados no mercado informal, saem por cerca de $20 \%$ a menos do preço vendido pelos lojistas, o que acaba se configurando, para muito deles, como uma concorrência desleal. Assim como no Brasil em Cabo Verde o mercado informal também tem conseguido absorver um número significativo da população local possibilitando emprego e renda. Mas, nem por isso tem deixado ser alvo de coerção por parte do governo.

De acordo com nota do secretário-geral da Câmara de Comércio, Indústria, Agricultura e Serviços de Barlavento, publicada no dia 10 de setembro de 2009 pelo jornal econômico OJE de Portugal, o comércio informal é estimulador de práticas ilícitas, além de prejudicar o clima de negócio e afetar a participação do país na Organização Mundial do Comércio. Adriano Cruz, então secretário, defendia a imposição de medidas de controle mais rígidas, já que grande parte das atividades é desenvolvida a partir das licenças facultativas concedidas pela câmara municipal e que não possue um perfil empresarial.

Furtado (2008, p. 32) assinala que a informalidade tem adquirido uma importância particular em Cabo Verde, seja na geração de empregos ou em rendimentos, sobretudo a partir dos anos de 1990 devido ao processo de privatização de empresas públicas e a terceirização de setores importantes do Estado. Outro elemento fomentador deste crescimento foi a implementação de programas da administração pública, que se traduziram em um não recrutamento de novos funcionários, especialmente aqueles que não reuniam um conjunto de requisitos definidos por lei, como por exemplo, níveis satisfatórios de educação formal. 
Ao analisar a questão da pobreza entre os agregados familiares chefiados por mulheres, o autor acima citado, percebe que embora os índices de analfabetismo tenham se tornado menos desiguais entre homens (17\%) e mulheres (19\%), à medida que aumenta o nível de escolaridade são os agregados chefiados por homens que estão mais representados: 10\% destes completaram o ensino secundário contra 5\% das mulheres. Essas desigualdades de gênero, também, se refletem dentre aqueles desempregados: a porcentagem das mulheres chefes de família nessa situação atinge $61 \%$ contra $41 \%$ dos homens.

Apesar do crescimento econômico, criação de empregos e luta contra a pobreza, é possível perceber que ocorreu uma lenta absorção da mão-de-obra feminina, mas que não possibilitou alterações significativas nas taxas de desemprego entre as mulheres. De acordo com Grassi (2003) são esses os fatores que vêm contribuindo para que um número considerável de cabo-verdianas se voltem para o comércio informal. Soma-se a isso, as dificuldades de encontrar trabalho em setores formais urbanos. Neste contexto que é possível situar as rabidantes: chefes de família, com baixa escolaridade que se voltam para a comercialização de produtos no mercado informal.

No caso brasileiro a vinda significativa dessas mulheres se dá em função de dois fatores específicos: a facilidade em obter o Visto e a questão da língua. 0 deslocamento para outras regiões, como por exemplo Estados Unidos, esbarra na dificuldade em adentrar o país e também no idioma, muitas delas mal sabem falar o português ${ }^{10}$. Atrelado a estes elementos o valor inicial no preço dos produtos, também, constituía um importante atrativo, como atesta a narrativa de Andrade, filho de uma importante ra- 
bidante que durante muitos anos comercializou produtos brasileiro em Cabo Verde.

[...] a primeira vez que a minha mãe migrou, veio para o Brasil pra comprar coisas pra revender em Cabo Verde, foi em 10 de agosto de 2002, que ela veio junto comigo também, entendeu, então a gente foi tipo recepcionado por algumas pessoas, mas o lado aventureiro falou um pouco mais agente veio simplesmente por férias e pra conhecer o lugar, agente foi pra uma pousada que fica logo ao lado de um dos grandes hotéis que a nosso ver era o hotel que todo cabo-verdiano quando saia de Cabo Verde ia pra lá é o Hotel Meridional que fica na avenida Dom Manoel, no centro da cidade, entendeu. [...] na época o que impulsionava muito mais este tipo de compra ao Brasil é o fato de que o dólar tava em ascensão, quando eu cheguei aqui o dólar tava qualquer coisa, três e tanto, entendeu, agente chegava com o nosso dinheiro, o dólar, trocava e dava muito dinheiro, entendeu, assim enchia os bolsos e vai gastando, e várias comerciantes vinham pra cá, aviões lotados, lotados mesmo, de comerciantes e aqui os produtos são baixos, os hotéis tem preços assim, super acessível e dá pra revender e ganhar um bom dinheiro realmente. $\mathrm{E}$ agente quando voltou levou algumas coisinhas, poucas, e já numa segunda volta a minha mãe veio fazer compras já foi pro meridional realmente, os funcionários já conhecem agente, já até entendem alguma coisa e os hotéis assim, normalmente ficam umas 3, 4 pessoas e a companhia que transporta agente é a TACV, Transporte Aéreo de Cabo Verde, entendeu [...] quando elas fazem o pacote pra vir pra Fortaleza, elas é... dão opção da pessoa já comprar com é, a reserva do hotel entendeu, então, tipo assim, já tem tipo que um vínculo entre a TACV e tipo esses hotéis aí, entendeu [...].

De fato a ascensão do dólar e, consequente, desvalorização do real, concedeu a essas mulheres um poder de compra significativo. Naquela conjuntura, os produtos saiam por um preço extremamente baixo, possibilitando um lucro considerável. Outro importante elemento importante presente neste depoimento 
diz respeito e estrutura montada pela TACV que recebia essas mulheres e acompanhavam até os locais de compra. Atualmente, já não existe mais essa organização, no entanto foi possível encontrar aquelas pessoas conhecidas como corretores, que ficam responsáveis em levar essas mulheres aos pontos de venda, em geral lugares com os quais possuem uma espécie de convênio e que recebem uma porcentagem sobre tudo que é comercializado.

Adailton, um dos primeiros corretores a agenciar as rabidantes, diz que chegou até essas mulheres por intermédio do dono de um importante Hotel ${ }^{11}$ e que desde então acompanha elas nas compras por Fortaleza. Em sua narrativa, acrescenta que dependendo das vendas visitam a cidade a cada 15 dias. Segundo ele, as comerciantes passam a semana inteira comprando pelos vários pontos da cidade, dentre os quais se destaca o Mercado Central, que possui muitas lojas de confecção, renda de bilro, redes, cerâmicas e todo tipo de artesanto produzido no Estado. Os produtos comercializados são de boa qualidade, em geral, advindos das cooperativas de trabalhadoras rurais, localizados no interior do Ceará.

Na realidade os artigos comercializados no Mercado Central são relativamente altos uma vez que estão voltados para os turistas, o que tem acarretado uma baixa no percentual de compra das rabidantes neste local. Não obstante, é no Centro de Pequenos Negócios de Vendedores Ambulantes de Fortaleza (CPNVA), ou Beco da Poeira, como é conhecido, o espaço que elas adquirem grande parte dos seus produtos. 0 local se destaca pela venda de roupas características da moda popular, as chamadas "modinha", geralmente composto por peças de malha feminina influenciadas pelos meios de comunicação, principalmente, as novelas. Essas peças, com grande circulação no mercado nacional, servem de referência para as cópias que serão reproduzidas em

11 Ao que tudo indica o hotel referido é o Meridional, anteriormente citado na fala de Andrade. 
larga escala, com um material de baixa qualidade e preços muito mais baratos do que aqueles encontrados nas grandes lojas.

O Beco da Poeira que não vende apenas produtos femininos, mas roupas masculinas, sapatos, bolsas, lingeries, biquínis, acessórios, celulares, relógios e até ervas medicinais, funciona de segunda a sábado, das 7 às 17 horas, em um prédio localizado na Avenida Imperador no centro da cidade. São aproximadamente 2.100 boxe, que medem cerca de $1,5 \mathrm{~m}^{2}$, construídos um ao lado do outro, formando inúmeros corredores estreitos. Em frente a cada um destes, quase sempre estão os comerciantes, sentados em um banquinho de madeira, esperando os clientes. Ao longo dos corredores os vendedores ambulantes oferecem caldos, sucos, água, refrigerantes, picolés e salgados. Na falta de espaço os clientes têm que provar as roupas nos corredores, em meio a toda essa movimentação.

É, também, na região central de Fortaleza, que está situada a Praça da Lagoinha, conhecida como "shopchão", onde ficam os pequenos comerciantes que na falta de barracas ou estandes de venda no Beco da Poeira, acabam por vender os seus produtos nas ruas transversais que cortam a avenida principal da cidade. As roupas e acessórios comercializados em geral são produzidos pelos próprios ambulantes ou são confeccionados por costureiras autônomas, que montam pequenas fábricas nos fundos das casas em bairros periféricos.

Todavia, vale ressaltar que nos últimos anos tem ocorrido uma queda na vinda dessas mulheres para o Brasil. De acordo com Conceição, rabidante de 38 anos, a carência de produtos novos e o aumento nos preços têm contribuído para essa redução. Ela acrescenta que "aqui se compra uma blusa de $\mathrm{R} \$ 40,00$ e você ainda tem que pagar hospedagem, excesso, alfândega [...] não tem como ter lucro!". Andrade, também, traz algumas informações importantes sobre a queda no poder de compra das rabidantes: 
[...] Mas, hoje em dia podemos dizer que o comércio feito pelas cabo-verdianas diminuiu pelo motivo que o dólar desceu muito, não tá sendo muito é... não tá sendo compensador vir pro Brasil, além do mais em Cabo Verde hoje em dia tamos tendo tipo que uma invasão, podemos falar do comércio chinês, entendeu, que tem visto os produtos que as comerciantes cabo-verdianas compram aqui e levam pra lá, eles compram uma ou duas peças, mandam pra China e desses produtos vem milhares, entendeu, a baixo custo, e tipo assim suponhamos, se tamos vendendo, porque a moeda é o escudo, se uma camisa tá valendo por mil e duzentos escudos, mil e quinhentos escudos eles vendem isso por cem escudos, duzentos escudos, você ver uma variação que, pô, o comerciante começa a ficar desanimado com esse tipo de comércio, porque você paga primeiro a passagem, gasta muito, entendeu, e chega lá a alfândega cai em cima, entendeu, e realmente isso tem também influenciado, não só a moeda que desceu mas, também o comércio também tá fraco, que quer dizer né, a situação tá ruim, ninguém tá comprando nada, as pessoas estão dizendo ah! Não tenho dinheiro, não tenho dinheiro e é realmente isso, a economia, o dinheiro tá lá mas tá vazando por outros lugares, então isso, é... a moeda estrangeira, o comércio dentro do país, as pessoas. Então tem feito com que é... as comerciantes diminuíssem a vinda.

A presença chinesa tem sido um fator recorrente em vários países do continente africano e em Cabo Verde tem exigido uma reestruturação nas lógicas comerciais internas, fazendo com que esses comerciantes concorram diretamente com as rabidantes ${ }^{12}$. Várias justificativas também podem explicar este fenômeno de recessão: o aumento do dólar, que reduziu drasticamente o poder de compra, assim como o lucro na venda de produtos pelas rabidantes; a carência de financiamentos que inicialmente elas recebiam de alguns bancos para efetivarem a comercialização; os convênios realizados com outros países, possibilitando e incentivando as trocas comerciais com novos parceiros; e, em

12 Para uma discussão mais aprofundada sobre o impacto dos comerciantes chineses sobre a rabidancia, ver Silva (2012). 
especialmente, o combate que os governos têm direcionado ao comércio informal.

Outro fator importante que permeou a narrativa acima e foi recorrente entre as rabidantes se refere às taxações e cobrança na alfândega, e o envio a partir do Brasil para Cabo Verde, quer seja quando a comerciante opta por carregar a bagagem junto ou através do despacho da carga por barcos, em contentores. No primeiro caso, a lucratividade maior é da empresa aérea que cobra em média cinco dólares por quilo em excesso, sendo que cada passageira tem direito até duas malas com 25 quilos cada. No segundo, o valor cobrado sai mais caro e é feito quando a carga transportada é significativa, e que chega a ser cobrado cerca de cinco mil dólares ${ }^{13}$.

No ato de desembarque em Cabo Verde ainda ocorre uma nova cobrança de taxação pela alfândega e que recai sobre as peças transportadas, isso nos casos em que a quantidade conduzida não chega aos 150 quilos. Em outros, quando ultrapassa este montante, é cobrada uma taxa que de $30 \%$ do valor comercial que é atribuído sobre o produto comercializado, aqui a cobrança é feita de forma mais rigorosa, embora isso venha depender das estratégias que podem ser utilizada no ato do despacho e do recebimento da mercadoria, como esconder produtos junto as roupas ou mesmo dá um "mó fitxadu" aos fiscais ${ }^{14}$.

O contexto acima exposto merece uma análise mais específica, que inclusive tem reforçado o debate referente à forma como

13 Em função do alto custo em "fazer um contetor", as rabidantes acabam por recorrer ao que elas denominam de "grupagem" ou "palete", quando o valor é divido entre um grupo de mulheres cujos produtos são transportados em um único contêiner.

14 Mão-fechada, expressão comum entre os cabo-verdianos, seria uma espécie de agrado que você dá a uma pessoa pelo serviço que lhe foi prestado. 0 jogo de palavras é exatamente para reforça o fato de ser algo feito no escondido e que conta com a colaboração dos fiscais. Para um debate mais aprimorado sobre essas questões, ver o trabalho de Francisco Rodrigues (2010) referente a corrupção nas alfândegas de Cabo Verde. 
pode ser concebida a prática desenvolvida pelas rabidantes, ou seja, como atividade formal e de acordo com as leis tributárias ou informal e isentas de taxações. Muniz (2008) assinala que esta não se enquadra nas regras que regulam as transações comerciais internacionais. Primeiramente, porque elas não podem ser caracterizadas nem como exportação direta, quando o próprio produtor-exportador a realiza de modo a estabelecer uma relação sem intermediação com a outra parte compradora; ou indireta, que decorre da relação produtor versus comprador, por meio de um interveniente com fim específico de exportar a mercadoria negociada e devidamente descrita na nota fiscal.

A legislação não considera como exportação o ato do estrangeiro comprar aqui produtos e conduzir ele próprio para o exterior, situação que ocorre quando essas mulheres transportam as mercadorias. Somente é considerado bagagem, e isenta de impostos, os bens cuja quantidade, natureza ou variedade não configurem importação ou exportação com fim comercial. Assim, de acordo o autor, estas não podem ser vistas na condição de exportadoras e sim de consumidoras normais. Logo, sobre toda e qualquer transação entre elas e as empresas, para caracterizar-se como um ato regular de comércio, deveria incidir os tributos inerentes à operação.

No tocante ao tratamento tributário e a incidência de impostos que é feita em Cabo Verde, segundo Muniz (2008), tem acarretado uma perda significativa por parte do governo brasileiro. As empresas com as quais essas mulheres comercializam também deixam de pagar os impostos exigidos para essas transações, uma vez que elas comercializam esses produtos em solo brasileiro, mas emitem notas fiscais como se estivessem exportando para Cabo Verde. No entanto, mediante o contexto acima exposto, pode-se verificar que ocorre a incidência de impostos e tributações sobre as mercadorias transportadas pelas rabidantes. Todavia esses elementos por se só não conseguem elucidar a complexidade dessa prática, em que o formal e o infor- 
mal estão imbricados e compõem o universo de atuação dessas mulheres.

Por fim, vale ressaltar que ainda existe uma certa confusão quando se tenta diferenciar o informal daquilo que seria formal. 0 setor informal é sempre difícil de definir. Em geral, considera-se que abrange todas as atividades econômicas que não pagam impostos. No entanto, as fronteiras entre os setores formal e informal ficam ambíguas, na medida em que há grandes empresas formais que fogem das suas obrigações fiscais, enquanto que muitos vendedores informais pagam diariamente taxas aos agentes municipais. Não obstante, em função da não existência de um conceito realmente satisfatória dos termos, optou-se por conceber essa prática como uma atividade informal, apesar de não concordar estritamente com a sua utilização.

\section{Referências Bibliográficas}

ANJOS, José Carlos Gomes dos. Intelectuais, literatura e poder em Cabo Verde: luta de definição da identidade nacional. Praia: INIPC, 2002.

BRASIL, Embaixada de Cabo Verde no Brasil disponível em http://www.embcv.org.br/portal/modules/news/idex.php?storytopic=7 acessado no dia $24 \mathrm{de}$ julho de 2010.

FURTADO, Cláudio. Dimensões da pobreza e da vulnerabilidade da pobreza em Cabo Verde: uma abordagem sistemática e interdisciplinar. Dakar: Codesria, 2008.

GRASSI, Marzia. Rabidantes: comércio espontâneo transatlântico em Cabo Verde. Portugal: Instituto de Ciências Sociais e Spleen Edições. 2003

HOPKINS, A. G. Les entrepreneurs africains et le développement de l'Afrique: une perspective historique. In: ELLIS, S.; FAURÉ, Y-A. Entreprises et entrepreneurs africains. L'Harmattan, 1995.

JORNAL OJE disponível em http://www.oje.pt/noticias/africa/comercio-informal-estimula-o-ilegal-e-prejudica-cabo-verde-na-omc-diz-camara-de-comercio, acessado no dia 28 de julho de 2010 
JORNAL O POVO disponível em http://opovo.uol.com.br/opovo/fortaleza282/780284.html acessado dia 17 de maio de 2010.

MUNIZ, Antônio. Tributação e comércio internacional informal: estudo das relações Cabo-Verde - Ceará. Dissertação de Mestrado. Programa de Pós-graduação em Constitucional. Universidade Federal de Fortaleza, 2008.

SANTANA, Ivo de. A experiência empresarial brasileira na África (1970 a 1990). Salvador: Ponto \& Vírgula, 2004.

SARAIVA, José Flávio Sombra. 0 Lugar da África: a dimensão atlântica da política externa brasileira de 1946 a nossos dias. Brasília: Editora da Universidade de Brasília, 1996.

SILVA, Tatiana Raquel Reis. A arte de comerciar: gênero, identidades e empoderamento feminino no comércio informal transatlântico das rabidantes cabo-verdianas. Tese de Doutorado. Programa de Pós-graduação em Estudos Étnicos e Africanos. Universidade Federal da Bahia, 2012.

Comércio (trans)atlântico: as rabidantes cabo-verdianas e o mercado informal brasileiro. Revista Outros Tempos, vol.8, no 12, dez. 2011. Disponível em http://www.outrostempos.uema.br/site/images/vol_8_num_12_2011/ dossie_03.pdf

Rabidantes: relações de gênero e comércio informal em Cabo Verde. Anais do VII Congresso Ibérico de Estudos Africanos. Portugal: CIEA 7, 2010.

Recebido em 02.03.2013

Aprovado em 23.05.2013 
